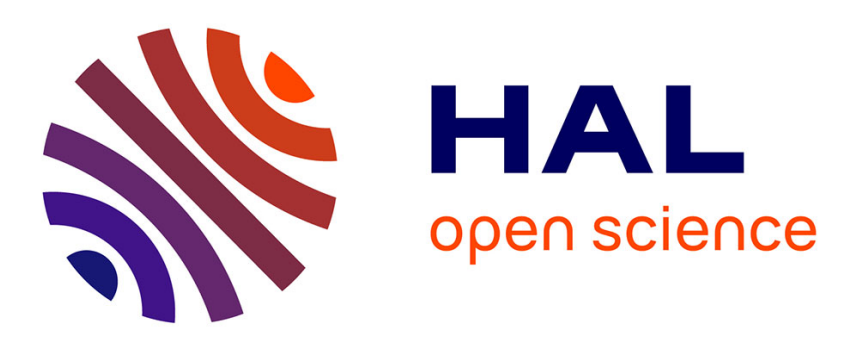

\title{
On the influence of buoyancy forces, failure strain and friction coefficient on the damage extent of a grounded ship
}

Herve Le Sourne, Jean-Philippe Pineau, C. B. Umunnakwe, Thomas Wesoly, Olivier Dorival

\section{To cite this version:}

Herve Le Sourne, Jean-Philippe Pineau, C. B. Umunnakwe, Thomas Wesoly, Olivier Dorival. On the influence of buoyancy forces, failure strain and friction coefficient on the damage extent of a grounded ship. 8th International Conference on Marine Structures (MARSTRUCT 2021), Jun 2021, Trondheim, Norway. hal-03357835

\section{HAL Id: hal-03357835 \\ https://hal.science/hal-03357835}

Submitted on 29 Sep 2021

HAL is a multi-disciplinary open access archive for the deposit and dissemination of scientific research documents, whether they are published or not. The documents may come from teaching and research institutions in France or abroad, or from public or private research centers.
L'archive ouverte pluridisciplinaire HAL, est destinée au dépôt et à la diffusion de documents scientifiques de niveau recherche, publiés ou non, émanant des établissements d'enseignement et de recherche français ou étrangers, des laboratoires publics ou privés. 


\title{
On the influence of buoyancy forces, failure strain and friction coefficient on the damage extent of a grounded ship
}

\author{
H. Le Sourne \& J.P. Pineau \\ GeM Research Institute \& ICAM, Nantes, France
}

C. B. Umunnakwe

ICAM, Nantes, France

T. Wesoly

ICAM, Toulouse, France

O. Dorival

Clement Ader Research Institute \& ICAM, Toulouse, France

\begin{abstract}
One of the causes for jeopardizing ship safety is accidental loading (impact) states such as collision and grounding which places the ship under possible total loss through hold/compartment flooding. Examination of existing literature on ship grounding simulation shows that most researchers assume the ship position as fixed and let the obstruction geometry to impact the ship model. Additionally, focus is usually either pure raking or pure stranding events and the effect of surrounding water is not considered. This paper is aimed to illustrate that in the event of grounding, the damage extent may be highly influenced by the ship heave motion that is mainly governed by the buoyancy forces. To do this, Ls-Dyna finite element code is used in conjunction with MCOL subroutine to account for external hydrodynamic forces. It is demonstrated that when a ship is given both surge and heave velocities at the instant of impact with the rock, multiple breaches may occur during the grounding event, resulting in an overall damage extent up to 4 times the one obtained when considering only ship horizontal raking motion. In addition, aside from ship external dynamics, the failure strain threshold value used in the material behavior law as well as the friction coefficient between the rock and the ship are shown to also have a significant influence on the grounded ship breach size.
\end{abstract}

\section{INTRODUCTION}

Over the years, there has been an increase in the demand for ship safety, ranging from the safety of people to environmental protection. Statutory rules and regulations have been put in place to quantify, minimize the risk, and therefore increase safety. One of the causes for endangering ship safety is accidental events such as collision and grounding (EMSA 2018). These accidents create scenarios for ship loss by outer bottom or side shell failure leading to water ingress followed by progressive flooding which possibly causes loss of reserve buoyancy and finally loss of vessel.

Ship grounding is a phenomenon whereby a ship impacts on seabed obstructions like rocks, shoals or reefs (Alsos \& Amdahl 2007). Thanks to advancements in computational power, nonlinear finite element analysis (NLFEA) of large ship structures subjected to rock impacts has been made practicable (Samuelides et al. 2007, Abubakar et al. 2013, Calle et al. 2017). Recently, a benchmark study has been carried out to compare numerical results with grounding experimental tests (Brubak et al. 2019), checking for the influence of key parameters such as friction coefficient and failure criteria considered when implementing the material behavior law. A good agreement with experimental tests was shown, which illustrates that NLFEA can be confidently used to estimate the ship damage extent in grounding scenarios. However, this benchmark study was not blind and, as already shown by (Marinatos \& Samuelides 2015, Calle \& Alves 2015) or (Prabowo et al. 2018), the choice of the failure threshold value and friction coefficient has a significant influence on the resulting breach size.

This work encompasses ship grounding simulations by considering external hydrodynamic forces. In most of the literature dealing with grounding analysis, the ship is supposed to be fixed in a position and the rock is moved and crushed against the ship bottom or side. It is thus considered that the effect of the surrounding water on the damage mechanisms is negligible. The reality is that the ship is free to move during and even after the impact and its movement is mainly governed by external hydrodynamic forces. It has been demonstrated, at least for ship-ship collisions, that the surrounding water plays an important role in terms of added mass, wave radiation damping and buoyancy forces, and to mention but a few in contribution to the dissipation of kinetic energy (Petersen 1992).

To account for the hydrodynamic effects, a subroutine named MCOL has been implemented in LSDyna finite element solver (Le Sourne et al. 2001, Ferry 2002). Based on numerical simulations using 
LS-Dyna/MCOL, the present work aims to investigate the influence of some parameters such as ship vertical motion, failure strain and friction coefficient on the grounded ship bottom damage.

\section{LS-DYNA/MCOL SOLVER}

In 1998, a first version of a rigid body dynamic solver named MCOL was developed by Mitsubishi and included as a subroutine in Ls-Dyna code. A few years later, by studying the rolling movement that may occur when the bulb of a surface ship impacts the conning tour of an immersed submarine, (Donner et al. 2001) showed that the difference of displacements between two colliding ships may lead to large amplitude rotational motions of the ships. That is why MCOL routine was entirely re-written in 2001 with the objective to include large rotational movements driven by both the crushing force and the hydrodynamic forces (added mass, wave radiation and buoyancy forces) as well as drag damping effects (Le Sourne et al. 2001). In LS-Dyna, the coupling between internal mechanics and external dynamics is thus as follows. At each time step, LS-Dyna calculates the contact force between the striking and struck ships (or between the rock and the grounded ship) as well as the corresponding moments with respect to the ship's center of gravity. The resulting load vector is then transferred to MCOL which solves, for each ship, the following 6 DOF equation:

$\left[M+M_{\infty}\right] \ddot{x}+G \dot{x}=F_{H}(x)+F_{W}(x)+F_{D}(x)+F_{C}$

where $M$ is the structural mass matrix, $M_{\infty}$ is the water added mass matrix, $x$ is the earth-fixed position of the center of mass of the ship, $G$ is the gyroscopic matrix, and $F_{H}, F_{W}, F_{D}$ and $F_{C}$ are the hydrostatic restoring, wave damping, drag damping and contact force vectors, respectively.

The new position, velocity and acceleration of the ship, solutions of equation (1), are then transmitted back to LS-Dyna for the next integration time step. Examples of using Ls-Dyna in conjunction with MCOL new version can be found in (Le Sourne et al. 2003, Le Sourne 2007, Paboeuf et al. 2015), and (Rudan et al. 2019). Finally, it is worth outlining that the use of MCOL functionality requires the availability of hydrodynamic data of the considered ships (added mass, wave damping and hydrostatic restoring matrices) that can be obtained using a seakeeping code.

\section{FINITE ELEMENT MODEL DESCRIPTION}

Let us consider two different ships: a RoPax and a Cruise Ship that are supposed to ground over a sharp rock. Their main particulars are listed in Table 1 and both ships are assumed to have the same double bottom scantling, which geometry is shown in figure 1 .

Table 1. Main particulars of the ships considered.

\begin{tabular}{|c|c|c|c|c|c|c|}
\hline Ship & $\begin{array}{c}\text { LOA } \\
(\mathrm{m})\end{array}$ & $\begin{array}{c}\text { Beam } \\
(\mathrm{m})\end{array}$ & $\begin{array}{c}\Delta \\
\text { (tons) }\end{array}$ & $\begin{array}{c}\mathrm{I}_{\mathrm{xx}} \\
\text { (tons.m }{ }^{2} \text { ) }\end{array}$ & $\begin{array}{c}\mathrm{I}_{\mathrm{yy}} \\
\text { (tons.m²) }\end{array}$ & $\begin{array}{c}\mathrm{I}_{\mathrm{zz}} \\
\text { (tons.m²) }\end{array}$ \\
\hline RoPax & 153 & 20 & 5,900 & $2.5610^{5}$ & $6.3810^{6}$ & $4.2310^{6}$ \\
\hline $\begin{array}{l}\text { Cruise } \\
\text { Ship }\end{array}$ & 241 & 32 & 34,000 & $4.110^{6}$ & $1.2210^{7}$ & $1.2610^{7}$ \\
\hline
\end{tabular}

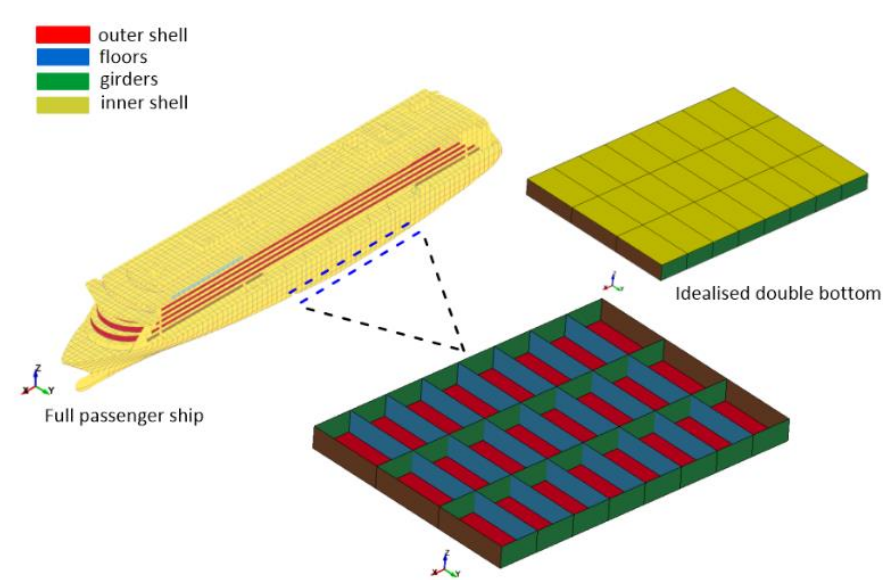

Figure 1: Idealized geometry of the double bottom

As highlighted in above figure, a $24 \mathrm{~m}$ long and $17.1 \mathrm{~m}$ wide section of the ship bottom is considered in the numerical analyses. For some grounding scenarios in which buoyancy forces lead to successive ship impacts against the rock, the section length is extended up to $72 \mathrm{~m}$. The distance between inner and outer shells is $1.6 \mathrm{~m}$ and the thickness of each member as well as the spacing between floors and between girders are listed in Table 2 . To complete the problem description, the seabed rock is idealized as a rigid cone with a half angle of $37^{\circ}$, a height of $3.5 \mathrm{~m}$ and a base diameter of $5.1 \mathrm{~m}$.

Table 2. Dimensions of double bottom structural members.

\begin{tabular}{lcc}
\hline Member & Thickness $(\mathrm{mm})$ & Spacing $(\mathrm{m})$ \\
\hline Outer shell & 15 & - \\
Inner shell & 10 & - \\
Floors & 15 & 3 \\
Girders & 20 & 5.7 \\
\hline
\end{tabular}

The double bottom section depicted in Figure 1 is meshed using reduced integrated Belytschko-LinTsai shell elements (LSTC 2019), with 5 integration points through thickness. Figure 2 gives an overview of the resulting finite element mesh and clearly shows that this latter is refined in the area where the double bottom will be in contact with the rock. The related element size $(30 \mathrm{~mm})$ has been obtained from a convergence analysis and complies with the recommendations given in (ISSC 2018).

As already mentioned, only a part of the ship double bottom is explicitly modelled using shell elements. The rest of the ship is represented by a rigid body "attached" to the extreme girders (see the nodes 
highlighted in red in Figure 2). This rigid body is characterized by its center of gravity and a mass and inertia matrix.

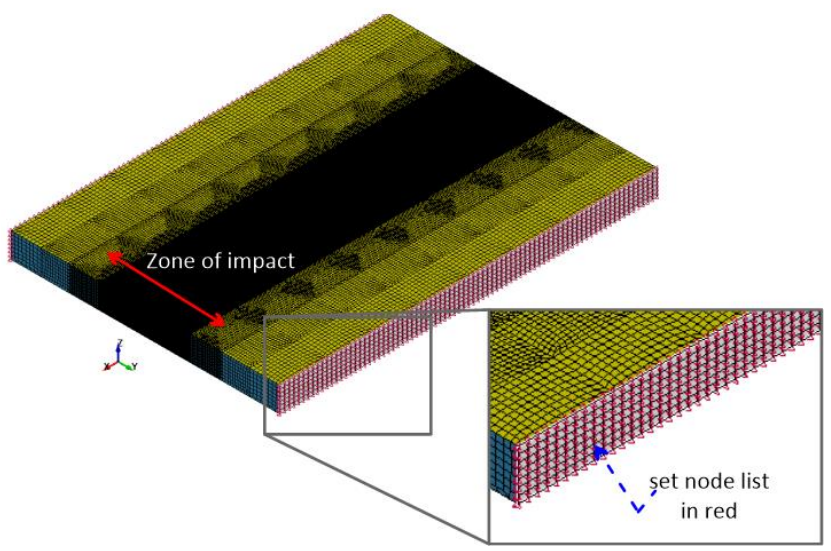

Figure 2. Finite element mesh of the double bottom

To model the behavior of the mild steel constituting the bottom, a piecewise linear isotropic hardening material law (Hallquist 2013) is adopted without considering the strain rate effect (Cerik \& Choung 2020). The material properties considered for the numerical simulations are shown in Table 3, where $E$ is the Young's modulus, $v$ is the Poisson's ratio, $\rho$ is the density, $\sigma_{y}$ is the yield stress and $E_{t}$ is the tangential modulus.

Table 3. Mild steel properties.

\begin{tabular}{cccccc}
\hline & $\begin{array}{c}E \\
(\mathrm{GPa})\end{array}$ & $v$ & $\begin{array}{c}\rho \\
\left(\mathrm{kg} / \mathrm{m}^{3}\right)\end{array}$ & $\begin{array}{c}\sigma_{y} \\
(\mathrm{MPa})\end{array}$ & $\begin{array}{c}E_{t} \\
(\mathrm{MPa})\end{array}$ \\
\hline Steel & 210 & 0.3 & 7850 & 240 & 1018 \\
\hline
\end{tabular}

The possible rupture of some components is accounted for by using an erosive law based on a shear criterion. The associated threshold failure strain $\varepsilon_{f}$ is determined according to Lehmann (2001):

$$
\varepsilon_{f}=0.056+0.54 \frac{t}{l_{e}}
$$

where $t$ is the plate thickness and $l_{e}$ is the finite element characteristic length. Resulting threshold values obtained for the different members of the double bottom are listed in Table 4. As the girders are supposed to deform mainly during the stranding phase through compression or folding modes, the erosive law is not applied to the related shell elements.

Table 4. Material effective plastic strain values used for each structural member.

\begin{tabular}{lccc}
\hline Member & $t(\mathrm{~mm})$ & $l_{e}(\mathrm{~mm})$ & $\varepsilon_{f}$ \\
\hline Outer shell & 15 & 42.4 & 0.247 \\
Floors & 15 & 42.4 & 0.247 \\
Girders & 20 & 42.4 &.- \\
Inner shell & 10 & 42.4 & 0.183 \\
\hline
\end{tabular}

As for the rock, it is considered that it is infinitely rigid and clamped into the seabed. Moreover, a "surface to surface" contact (Hallquist 2013) is defined between the ship bottom and the rock and an "auto- contact" between the different members of the ship structure, both with a friction coefficient of 0.3 . Finally, hydrodynamic data of the considered ships (water added mass, wave damping and hydrostatic restoring matrices) have been obtained using Hydrostar seakeeping code from Bureau Veritas (2019).

\section{NUMERICAL RESULTS}

\subsection{Influence of the heave motion on ship bottom damage extent}

Let us call Pure raking the horizontal crushing process of the bottom during the ship surge motion. Such deformation occurs when the vessel moves horizontally during all the grounding events. Whatever the ship considered in this study, it is given a horizontal initial velocity $V x=1.5 \mathrm{~m} / \mathrm{s}$ and the location of the impact with the rock is supposed to occur in-between two girders as shown in the left-hand side of Figure 5. Furthermore, when setting the position of the bottom meshed section with respect to the overall ship, it is assumed that its center is located exactly below the ship's center of gravity.

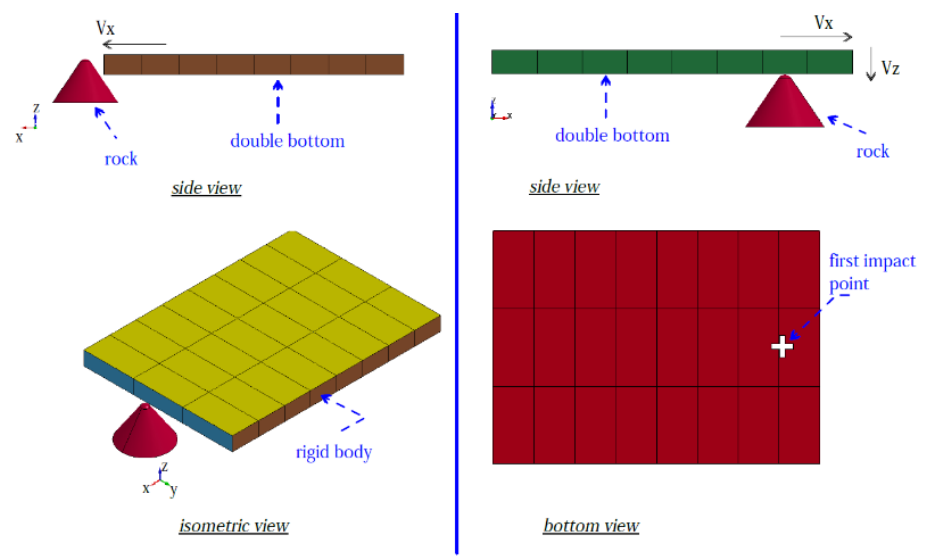

Figure 5: Pure raking scenario (left) and Combined strandingraking scenario (right)

The deformation modes post-processed from cruise ship pure raking simulation are illustrated in Figure 6. Due to the nature of the rock and the impact speed, the first two floors are torn into two at the point of impact and the remaining six floors are consecutively stretched and cut. The major failure mode for the outer shell plating is tearing which is followed by folding and crushing of the plate. During the raking scenario, the folding of the outer plating as the ship runs over the rock gradually increases the volume of the structural members involved in resisting the penetration at a point in time. This contributes to the increase in structural resistance at this instant before complete crushing is achieved.

On the other hand, a second grounding scenario where the ships are imposed with both a surge initial velocity $\mathrm{Vx}=1.5 \mathrm{~m} / \mathrm{s}$ (the same as Pure raking scenario) and a heave initial velocity $V z=-0.75 \mathrm{~m} / \mathrm{s}$ is investigated. This situation might happen when the 
ship, navigating in the presence of waves, is subjected to upward and backward heave motions. As shown on the right-hand side of Figure 5, the first impact with the rock is assumed to occur on the outer shell plating in-between two longitudinal girders.

This second scenario is referred to as Combined stranding raking.

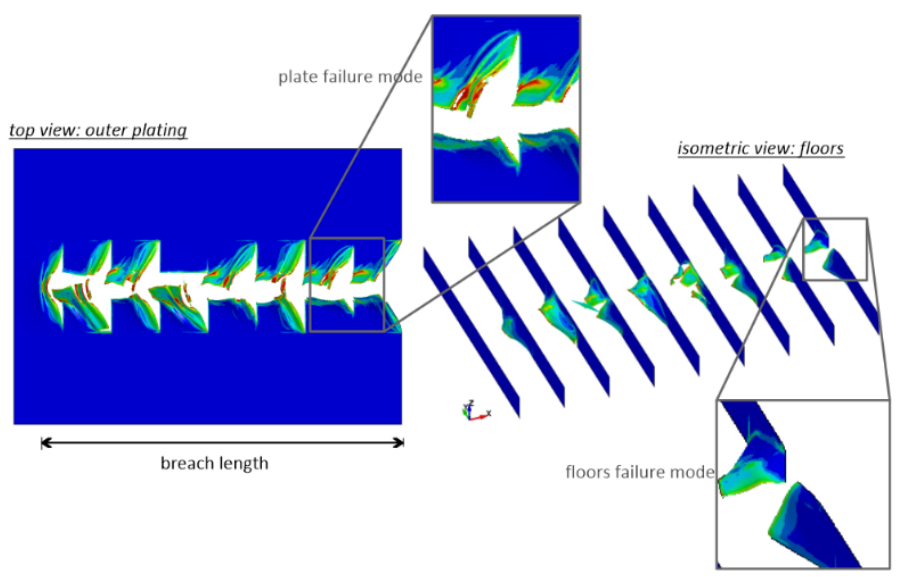

Figure 6. Cruise ship pure raking failure modes

As for the Pure raking scenario, the meshed bottom section is supposed to be located exactly below the ship center of gravity.

The deformation modes post-processed from LSDyna/MCOL simulation are illustrated in Figure 7. Due to the initial vertical velocity and the action of both the gravity and buoyancy force, the ship has a downward and upward movement leading to multiple breaches instead of a continuous one. Each stranding movement of the ship creates a breach on the hull bottom, crushing one or several floors according to the rock location.

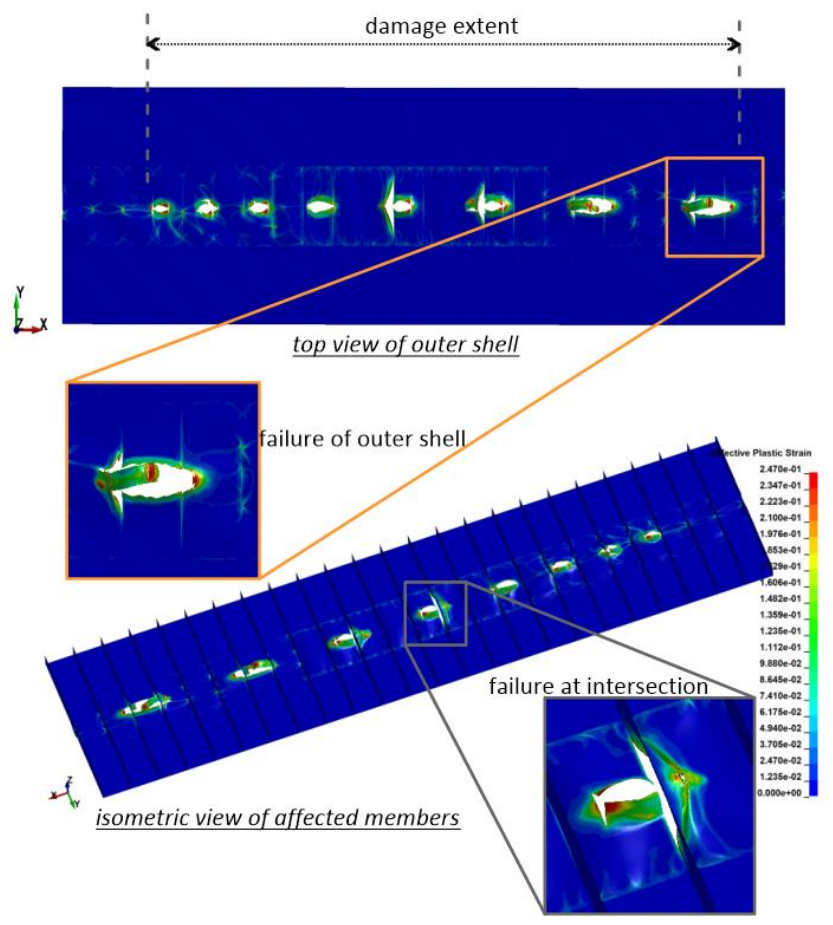

Figure 7. Cruise ship combined stranding-raking failure modes
The ship's downward and upward heave motion is also illustrated by the kinetic energy time history plotted in Figure 8. Here, one vertical oscillation of the ship corresponds to two oscillations of the kinetic energy curve. Moreover, one observes in Figure 8 that the successive increases of internal and sliding energies correspond to the successive indentations of the rock into the bottom structure. At the end of the simulation, the surge movement of the ship has almost vanished, but this latter conserves some kinetic energy due to some remaining heave and pitch oscillating motions. From Figure 8, it is observed that 70s are necessary to stop the ship surge movement, while in the Pure raking scenario, all the kinetic energy is continuously transferred to deformation and sliding energies in only 20 s.

Of course, resulting damage extent, highlighted in Figure 7, is much more important when surge and heave motions are combined. In Table 5, the damage extent is compared to the continuous breach length such as defined in Figure 6. It appears that for both ships considered, the damage extent is at least 4 times higher than the length of the continuous breach postprocessed from Pure raking simulations. One practical consequence is that although the water ingress process will probably take more time in a Combined standing-raking scenario, the number of flooded compartments will certainly be more important and, as a consequence, the stability of the ship after accident will probably be more critical.

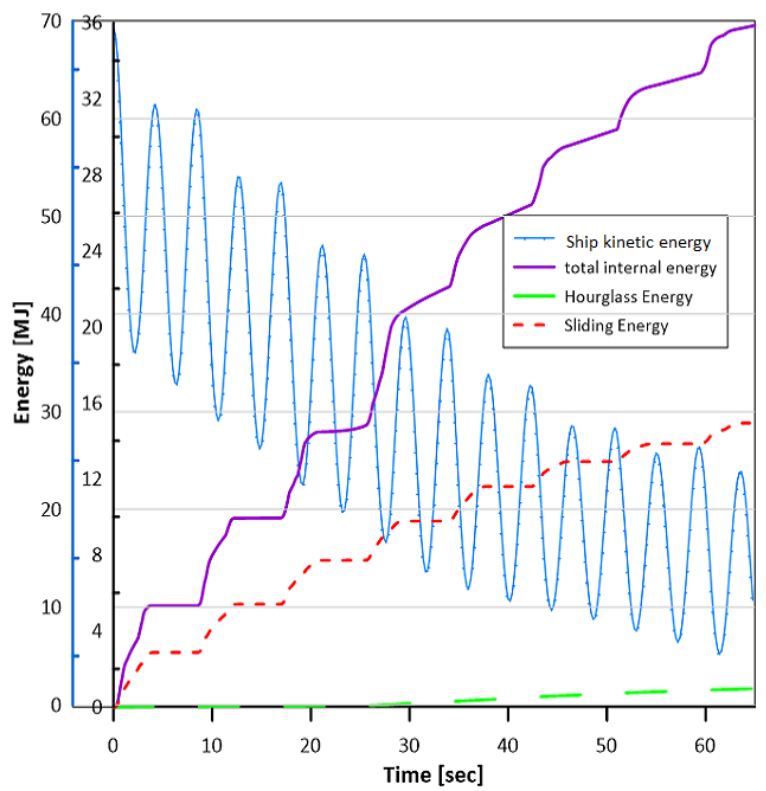

Figure 8. Cruise ship combined stranding-raking: energy time histories (the kinetic energy has been plotted with a different $y$-axis colored in blue to clarify the representation)

Table 5: Bottom damage extent: comparison between Pure raking and Combined stranding raking numerical simulation results.

\begin{tabular}{lcccccc}
\hline & \multicolumn{3}{c}{ RoPax } & \multicolumn{3}{c}{ Cruise ship } \\
& raking & comb. & ratio & raking & comb & ratio \\
\hline Extent $(\mathrm{m})$ & 3.9 & 16.4 & $>4$ & 15 & 59.3 & $\approx 4$ \\
\hline
\end{tabular}




\subsection{Influence of the threshold failure strain and friction coefficient on ship bottom damage extent}

The same double bottom finite element model is used to study the influence of both the failure strain threshold value and the friction coefficient on the breach length. The RoPax ship which particulars are defined in Table 1 is assumed to impact at $3 \mathrm{~m} / \mathrm{s}$ the conical rock defined in Section 3 in a Pure raking scenario. In all the simulations, the penetration height of the rock into the ship is taken equal to $1.24 \mathrm{~m}$, so the rock does not crush the double bottom.

First, three different failure strain threshold values (F.S.) are considered for the sensitivity analysis, keeping the friction coefficient between the outer shell and the rock equal to 0.3 . While case 0 corresponds to the simulation based on the threshold failure strain values defined according to Equation (3) and Table 4, case 1 and case 2 are defined by respectively decreasing and increasing these values by $10 \%$. As shown in Figures 9a and 9c, the bottom platting fails along two girders in cases 0 and 2, while the rupture initiates and propagates in front of the rock for case 1 (Figure 9b).
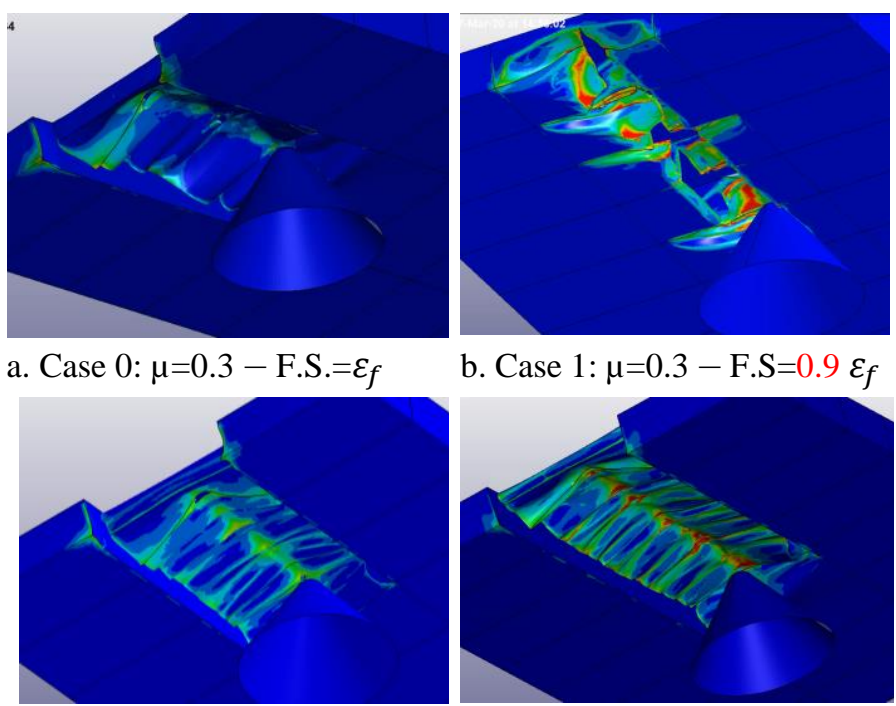

c. Case $2: \mu=0.3-\mathrm{F} . S=1.1 \varepsilon_{f}$

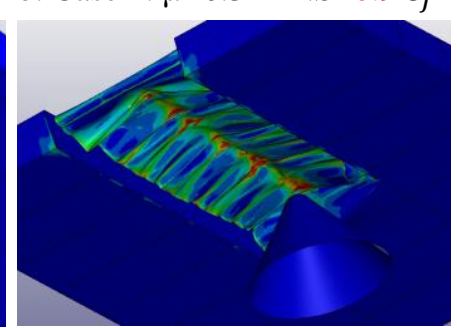

d. Case 3: $\mu=0.1-$ F.S $=\varepsilon_{f}$

Figure 9: Pure raking damage patterns

Taking the case 0 as reference, Table 6 shows that the breach length is increased by $34 \%$ when F.S. is decreased by $10 \%$. It is also observed that although the failure mode is the same in cases 0 and 2, increasing the failure strain by $10 \%$ leads to a $13 \%$ decrease in the breach length.

From this sensitivity analysis, it can be concluded that in the FE model, at least two failure scenarios are competing, namely a failure developing along the girders (due to transverse tension and bending), and crack initiating and propagating in the zone of impact with the rock (due to local strains). A third scenario of failure has also been observed in other simulations (not shown here) that involves a failure in the form of two parallel longitudinal cracks on both sides of the cone, leaving the panel with a band of material in the middle. All the scenarios have been found to occur, or not, due to relatively small change $(+/-10 \%)$ in the critical failure strain; the simulation sometimes jumps from one scenario to another.

The energy dissipated during the different scenarios can be very different because they involve large variations in the contact forces (hence in the energy dissipated by friction) and in the deformation of the structure, in particular the amount of bending and tension (hence the dissipation due to plasticity). For this reason, the breach length has been found to be drastically dependent on the critical failure strain.

From an engineering point of view, this emphasizes the need to control the failure scenarios in a more robust manner in order to both capture the actual failure mechanisms independently of the mesh size and with the correct constitutive model (strain rate effects, triaxiality effects, etc.) and elements formulations (shell formulations, integration points, etc.).The significant sensitivity of the grounding damage to the erosive shear failure criterion clearly shows that this latter is probably insufficient to accurately model the different failure mechanisms (tension, tearing, bending plastic hinges) occurring in such raking process.

Second, the influence of the friction coefficient investigated by running case 0 scenario with modified friction of $\mu=0.1$ (case 3). Comparing the damage patterns presented in Figures 9a and 9d, it is observed that the bottom plating tears along the girders in both scenarios. However, Table 6 shows that the distribution of the dissipated energy between deformation and sliding mechanisms is different. While the sliding energy represents $26 \%$ of the total dissipated energy in case 0 , it represents only $11 \%$ when the friction coefficient is set to 0.1 . As a consequence, a higher part of the initial kinetic energy is transferred to deformation energy and resulting breach extent is increased by $31 \%$.

Table 6: Sensitivity to failure strain threshold value

\begin{tabular}{clccc}
\hline Case & Description & $\begin{array}{c}\text { Breach } \\
\text { length }(\mathrm{m})\end{array}$ & $\begin{array}{c}\text { Disc } \\
/ \text { case 0 }\end{array}$ & $\begin{array}{c}\text { Sliding } \\
\text { ratio }\end{array}$ \\
\hline 0 & $\mu=0.3-\mathrm{F} . \mathrm{S}=\varepsilon_{f}$ & 11.2 & - & $26 \%$ \\
1 & $\mu=0.3-\mathrm{F} . \mathrm{S}=0.9 \varepsilon_{f}$ & 15.0 & $+34 \%$ & $33 \%$ \\
2 & $\mu=0.3-\mathrm{F} . \mathrm{S}=1.1 \varepsilon_{f}$ & 9.9 & $-13 \%$ & $25 \%$ \\
3 & $\mu=0.1-\mathrm{F} . \mathrm{S}=\varepsilon_{f}$ & 14.7 & $+31 \%$ & $11 \%$ \\
\hline
\end{tabular}

Again, this brief sensitivity analysis clearly shows that the friction coefficient has a significant effect on the length of the breach resulting from the grounding of a ship on a sharp rock. As this coefficient mainly depends on the nature of the rock encountered by the ship, it is recommended to try different friction 
coefficients when performing such kind of numerical analysis.

\section{CONCLUSIONS}

In this work, several ship bottom grounding scenarios have been scrutinized considering two different passenger ships: a RoPax (around 6,000 tons) and a cruise ship (around 34,000 tons). Based on NLFEA, the influence of external hydrodynamic forces on the damage extent during the grounding event has been investigated. It has been demonstrated that when the ship is given both horizontal and vertical velocities just before the impact with the rock, it is subjected to both raking and stranding processes and the action of buoyancy forces leads to several breaches at the end of event. For both ships considered in this analysis, it appeared that the overall damage extent can be 4 times higher than the length of the continuous breach post-processed from pure raking simulations. From a practical point of view, this means that a larger number of compartments are liable to get flooded and the stability of the ship after accident is likely to be more critical.

Another part of the presented work has been dedicated to analyzing the influence of both the failure strain and friction coefficient considered in the simulations on pure raking scenario. The length of the breach resulting from the grounding of a ship on a sharp rock has been shown to be significantly sensitive to both parameters. The main conclusions from this sensitivity analysis are finally drawn:

- The shear failure criterium commonly used in such numerical analysis is probably insufficient to accurately model the different failure mechanisms occurring in a ship raking process.

- As the friction coefficient mainly depends on the nature of the rock, it is recommended to try different values for the friction when performing such numerical analyses.

\section{ACKNOWLEDGMENTS}

The research presented in this paper has been carried out under project Flooding Accident Response (FLARE) number 814753, under H2020 program funded by the European Union.

\section{REFERENCES}

AbuBakar, A., Dow, R.S. (2013) Simulation of ship grounding damage using finite element method. Internation Journal of Solids and Structures (50): 623-636
Alsos, H.S. \& Amdahl, J. 2007. On the resistance of tanker bottom structures during stranding. Journal of Marine Structures (20): 218-237.

Brubak, L., Hu, Z., Kõrgesaar, M, Schipperen I., \& Tabri K. 2019. Numerical Simulations of Grounding Scenarios Benchmark study on key parameters in FEM modellings. $14^{\text {th }}$ Practical Design of Ships and Other Floating Structure International Conference (PRADS): 257-269.

Bureau Veritas 2019. Hydrostar for experts user manual. Bureau Veritas, Paris, France.

Calle, M.A.G., \& Alves M. 2015. A review -analysis on material failure modeling in ship collision. Ocean Engineering: 2038

Calle, M.A.G., Oshiro, R.E. \& Alves M. 2017.Ship collision and grounding: Scaled experiments and numerical analysis. International Journal of Impact Engineering (103), 195210.

Cerik, BC. \& Choung, J. 2020. On the modelling of strain-rate effects in nonlinear FE analysis of ship collisions, International Conference on Ships and Offshore Structures: 217-232

Donner E.R., Besnier, F. \& Le Sourne, H. 2001. Numerical simulation of ship-submarine collisions. Proceedings of Practical Design of Ships and Other Floating Structure International Conference (PRADS) (2): 1309-1314.

European Maritime Safety Agency EMSA 2018. Annual Overview of Marine Casualties and Incidents. http://www.emsa.europa.eu/emsa-documents/latest/item/ 3406-annual-overview-of-marine-casualties-andincidents-2018.html

Ferry, M., Le Sourne, H. \& Besnier, F. (2002). MCOL theoretical manual. Principia Marine Report, Nantes, France.

Hallquist, J.O. 2013. LS-DYNA theory manual. Livermore Software Technology Corporation, California, USA

ISSC Committee V.1 - Accidental Limit States. 2018. Proceedings of the 20th International Ship and Offshore Structures Congress (II) - M.L. Kaminski and P. Rigo (Eds.), The authors and IOS Press.

Le Sourne, H., Donner R., Besnier, F. \& Ferry, M. 2001. External Dynamics of Ship-Submarine Collision. Proceedings of the $2^{\text {nd }}$ International Conference on Collision and Grounding of Ships (ICCGS): 137-144.

Le Sourne, H., County, N., Besnier, F., Kammerer, C. Legavre, H. 2003. LS-DYNA Applications in Shipbuilding. Proceedings of the $4^{\text {th }}$ European LS-DYNA Users Conference: 1-16.

Le Sourne, H. 2007. A ship collision analysis program based on super-element method coupled with large rotational ship movement analysis tool. Proceedings of the $4^{\text {th }}$ International Conference on Collision and Grounding of Ships: 131-138.

LSTC 2019. LS-Dyna keyword user's manual. Livermore Software Technology Corporation, California, USA.

Marinatos, J.N., Samuelides M.S. 2015. Towards a unified methodology for the simulation of rupture in collision and grounding of ships. Marine Structures (42):1-32

Paboeuf, S., Le Sourne, H., Brochard, K., \& Besnard, N. 2015. A damage assessment tool in ship collisions. Proceedings of the Damaged Ship III conference - The Royal Institution of Naval Architects: 25-26.

Petersen M.J. 1992. Dynamics of ships collision. Ocean Engineering (9): 259-329

Prabowo, A. R., D. M. Bae, J. H. Cho, and J. M. Sohn. 2018 
Characteristic of double bottom responses under poweredhard grounding scenario with idealised rock indenter. International Journal of Structural Engineering (9): 130145

Rudan, S., Ćatipović, I., Berg, R., Völkner, S., \& Prebeg, P. 2019. Numerical study on the consequences of different ship collision modelling techniques. Ships and Offshore Structures (14), 387-400.

Samuelides, M.S., Voudouris , G., Toulios, M., Amdahl, J. Dow. 2007. Simulation of the behaviour of double bottoms subjected to grounding actions. Proceedings of the $4^{\text {th }}$ International Conference on Collision and Grounding of Ships, Hamburg: 93-102 